\title{
Spigelian Hernia: A Rare Hernia With Peculiar Anatomy. (Case Report And Review Of Literature)
}

\author{
Ketan Vagholkar
}

\begin{abstract}
Background: Spigelian hernia best described as spontaneous lateral ventral hernia is an extremely rare type of hernia. The anatomical peculiarities and diagnostic challenges need to be understood in order to surgically mange this hernia.

Introduction: Spigelian hernia occurs through a defect in the spigelian fascia typically lying in the spigelian zone.

Case report: A case of a large incarcerated spigelian hernia is presented to highlight the diagnostic and anatomical peculiarities of this hernia.

Discussion: The anatomical basis of this hernia along with clinical presentation, diagnostic modalities and treatment options is discussed.

Conclusion: Clinical suspicion confirmed by imaging is necessary for diagnosis. Surgery is the mainstay of treatment.
\end{abstract}

Index Terms-About four key words or phrases in alphabetical order, separated by semi commas.

\section{INTRODUCTION}

Spigelian hernia is a protrusion of pre peritoneal fat, peritoneal sac or viscera through a defect in spigelian fascia. It constitutes $0.12 \%$ of all abdominal wall hernias. [1] These hernias usually lie in the so called spigelian hernia belt. The hernia is named after Adriaan van der Spieghel who discovered the semi lunar line in 1645. [1,2] Joseph Klinkosch was the first to describe spigelian hernia as a defect in the semi lunar line in 1764.[1] Since this herniation takes place into a closed space, the presentation many a times may be subtle thereby making diagnosis difficult.

A case of a large incarcerated spigelian hernia is presented along with a brief review of literature to create an awareness about the anatomical basis, clinical intricacies and surgical options for managing this extremely rare and elusive type of hernia.

\section{CASE REPORT}

A 43 year old male patient presented with history of a bulge in the right side of the lower abdomen since 7 years. The size of the bulge had increased over a period of time. (Figure 1) Initially the bulge used to reduce on lying supine. However over the last 2 years the bulge did not reduce on lying down. The patient complained of intermittent pain and discomfort. There were no features suggestive of frank obstruction. There was no history of trauma, surgery, any precipitating factor or any medical co-morbidities.

Physical examination of the bulge in standing position revealed a visible and palpable impulse on coughing. The

Published on December 24, 2019.

Ketan Vagholkar, Department of Surgery D.Y.Patil University School of Medicine Navi Mumbai, India.

(e-mail: author@ boulder.nist.gov) swelling was irreducible on lying down in supine position.

There were no swellings in the groin or in the midline. A contrast enhanced computed tomography (CECT) was done which revealed a large spigelian hernia on the right side. The contents were small bowel loops and omentum which were typically lying in the plane between the oblique muscles of the abdomen (Figure 2).

The patient underwent open hernioplasty. An oblique incision was made over the convexity of the swelling in the right lower abdomen. External oblique aponeurosis was opened. (Figure 3) The hernia sac identified and dissected all around till the neck was reached. The defect was in the internal oblique aponeurosis at the medial end. (Figure 4) The sac was opened. (Figure 5) Adherent bowel loops dissected free of adhesions and reposited back into the peritoneal cavity. Redundant sac trimmed and closed with 10 vicryl. (Figure 6) The defect was closed with interrupted 1-0 polypropylene sutures. (Figure 7) A polypropylene mesh place over the defect and fixed with non-absorbable sutures. (Figure 8) A negative suction drain was placed over the mesh and brought out through a separate incision. The external oblique muscle was closed with 1-0 vicryl. Subcutaneous tissues approximated with 2-0 vicryl and skin approximated with staples. The negative suction drain was removed after 48 hours and the patient discharged on the third day after surgery. Skin staples were removed on the tenth postoperative day. Patient has been following up for last six months with no evidence of recurrence.

\section{DISCUSSION}

The anatomy of the anterior abdominal wall in the lower part of abdomen needs reappraisal in order to diagnose and manage a spigelian hernia.[3] The internal oblique aponeurosis splits into two leaves, anterior leaf and posterior leaf along a line called linea semilunaris which lies lateral to rectus abdominis muscle. The posterior rectus sheath becomes deficient approximately 1.5 inch below the umbilicus along a curved line called linea semicircularis. The intersection of the linea semilunaris and linea semicircularis is called the spigel's point. This is an area of potential weakness and the commonest site for spigelian hernia. Embryologically a spigelian hernia may develop through weakened areas in continuation of aponeurosis of layered abdominal muscles as they develop separately in the mesenchyme of somatopleura originating from various myotomes. [3] The hernia is best described to arise from spigelian hernia belt which is a transverse $6 \mathrm{~cm}$ wide zone above the interspinous plane. The hernial ring is a welldefined defect in the aponeurosis. The sac is surrounded by extraperitoneal fat which invades the inter-perietal region 
through the transversus and internal oblique aponeurosis thereafter spreading beneath the intact aponeurosis of the external oblique or rarely lying in the rectus sheath lateral to the rectus muscle. [4]

The hernia usually appears in the 4th to 7th decade of life with female preponderance. [1, 4] Spigelian hernias are rarely encountered in children. However if found in children then they are associated with an undescended testis. [4] Perforating vessels may weaken the area in the spigelian fascia thereafter leading to herniation. Stretching of abdominal wall due to increased intraabdominal pressure with chronic cough in COPD, ascites, obesity, multiple pregnancies, previous surgery or scarring including chronic ambulatory peritoneal dialysis all very strongly predispose to the development of spigelian hernia. Patients suffering from collagen disorders like Ehler Danlos syndrome may exhibit a very high incidence of such a rare hernia. [4]

Diagnosis of this hernia is usually difficult as there are no classic symptoms or signs due to the interparietal location of hernial sac. However in the case presented the location of the bulge with features suggestive of a hernia enabled a preimaging diagnosis. Only $50 \%$ of cases are diagnosed preoperatively as a swelling being present just above iliac prominence on standing and disappearing partially or fully on lying down as in the case presented. Rarely the hernia can enter the rectus sheath thereby being confused with spontaneous rupture of the rectus muscle or hematoma of the rectus sheath. However the diagnosis can be confirmed by imaging. USG is the first investigation of choice. [5] Ultrasound scanning of the semilunar line should be undertaken in all patients presenting with lateral bulge of body wall accompanied with vague abdominal pain. Few patients may present with a classic mass that becomes prominent in upright position and in supine position while performing a Valsalva maneuver. Contrast enhanced computerized tomography (CECT) remains the investigation of choice for diagnosing a spigelian hernia.[6] The exact site and size of defect, pattern of herniation, contents of sac and their vascularity can all be ascertained. This provides a roadmap for planning of further treatment. MRI will be useful in a few cases. However CECT is superior to MRI. [6] CECT helps in differentiating spigelian hernia from other conditions such as tumors of abdominal wall or spontaneous hematomas of the rectus sheath. Chances of strangulation in spigelian hernia is extremely high due to sharp fascial margins around the defect along with interparietal course of the hernia sac. Occasionally, a Richter type of a hernia may also be encountered. [7]

Surgery is the mainstay of treatment. [7, 8] This may be either open or laparoscopic. Open anterior hernioplasty is a safe and time tested technique yielding excellent results as was done in the case presented. A curved horizontal incision is be made over the swelling. External oblique aponeurosis opened, sac identified and dissected up to neck. The sac is then opened. Contents reposited into the abdomen followed by closure of the sac. The defect can be closed with nonabsorbable sutures. A mesh is the placed covering the area of defect with circumferential overlap of $3 \mathrm{~cm}$ to $5 \mathrm{~cm}$ and fixed with non-absorbable suture material. The aponeurosis of external oblique is closed over the mesh followed by approximation of subcutaneous tissues and skin.
Laparoscopic approaches include intraperitoneal and extra peritoneal approach. [9, 10] Intraperitoneal is a simple method. But it unnecessarily converts a parietal wall surgery to an intraabdominal surgery thereby increasing the risk of damage to the intraabdominal viscera. The mesh can be placed intraperitoneally or extraperitoneally by creating a flap of the peritoneum transabdominally and then closing it after fixing the mesh. [9] Total extraperitoneal approach is preferred to intraperitoneal approach as intestinal obstruction and fistulation of bowel is avoided by virtue of the mesh being in an extra-peritoneal position. [10, 11] Robotic repair of spigelian hernias have been done. [12] However there is no consensus yet as to which method is superior.

\section{CONCLUSION}

Spigelian hernia is one of the rare types of abdominal wall hernias.

Clinical diagnosis is elusive due to the interparietal location of the sac with contents.

CECT is diagnostic and provides a road map for planning the treatment.

Both open and laparoscopic approaches may be used for treating spigelian hernia.

\section{CONCLUSION}

A conclusion section is not required. Although a conclusion may review the main points of the paper, do not replicate the abstract as the conclusion. A conclusion might elaborate on the importance of the work or suggest applications and extensions.

\section{ACKNOWLEDGMENT}

We would like to thank the Dean of D.Y.Patil University School of Medicine, Navi Mumbai, India for allowing us publish this case report. We would also like to thank Parth Vagholkar for his help in typesetting the manuscript.

\section{REFERENCES}

[1] Spangen L. Spigelian hernia. World J Surg. 1989; 13(5):573-580. doi: 10.1007/BF01658873.

[2] Sachs M, Linhart W, Bojunga J. The so-called Spigelian hernia--a rare lateral hernia of the abdominal wall. Zentralblatt fur Chirurgie. 1998; 123(3):267-271.

[3] Skandalakis PN, Zoras O, Skandalakis JE, Mirilas P. Spigelian hernia: surgical anatomy, embryology, and technique of repair. Am Surg. 2006; 72(1):42-48.

[4] Webber V, Low C, Skipworth RJE, Kumar S, de Beaux AC, Tulloh B. Contemporary thoughts on the management of Spigelian hernia. Hernia. 2017 Jun; 21(3):355-361.

[5] Smereczyński A, Kołaczyk K, Lubiński J, Bojko S, Gałdyńska M, Bernatowicz E. Sonographic imaging of Spigelian hernias. J Ultrason. 2012 Sep; 12(50):269-75

[6] Gough VM, Vella M. Timely computed tomography scan diagnoses spigelian hernia: a case study. Ann R Coll Surg Engl. 2009; 91(8):W9-10. doi: 10.1308/147870809X450629.

[7] Larson DW, Farley DR. Spigelian hernias: repair and outcome for 81 patients. World J Surg. 2002 Oct; 26(10):1277-81.

[8] Polistina FA, Garbo G, Trevisan P, Frego M. Twelve years of experience treating Spigelian hernia. Surgery. 2015 Mar; 157(3):54750.

[9] Mittal T, Kumar V, Khullar R, Sharma A, Soni V, Baijal M, Chowbey PK. Diagnosis and management of Spigelian hernia: a review of literature and our experience. J Minim Access Surg. 2008; 4(4):95-98. doi: 10.4103/0972-9941.45204. 
[10] Moreno-Egea A, Carrasco L, Girela E, Martín JG, Aguayo JL, Canteras M. Open vs laparoscopic repair of spigelian hernia: a prospective randomized trial. Arch Surg. 2002 Nov; 137(11):1266-8.

[11] Moreno-Egea A, Flores B, Girela E, Martin JG, Aguayo JL, Canteras M. Spigelian hernia: bibliographical study and - presentation of a series of 28 patients. Hernia. 2002; 6(4):167-170. doi: $10.1007 /$ s10029002-0077-x.

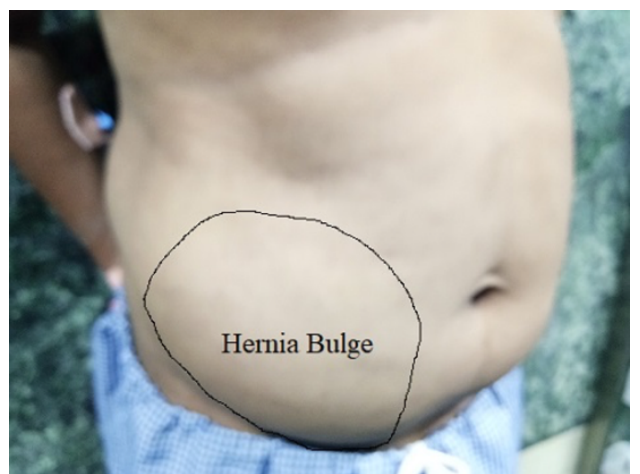

Fig. 1. Lateral bulge seen in the right lower abdomen.

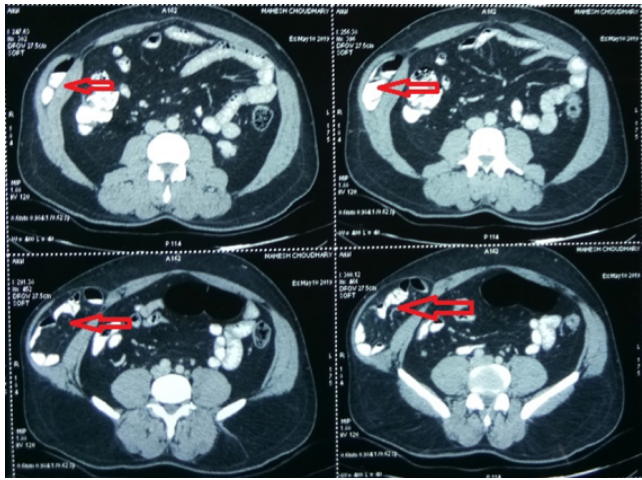

Fig. 2. CECT showing an incarcerated Spigelian hernia.

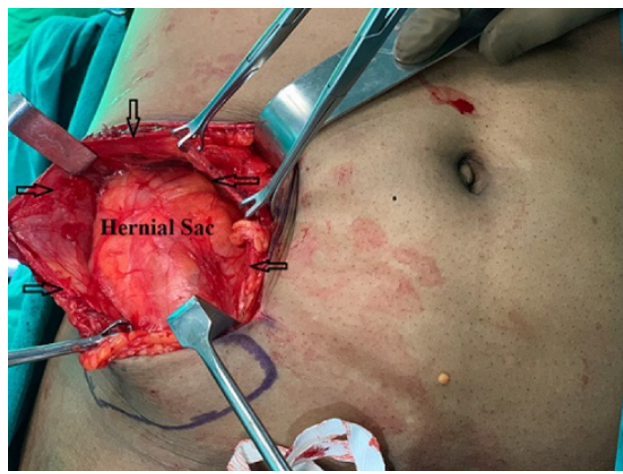

Fig. 3. Hernia sac displayed after opening the external oblique aponeurosis.

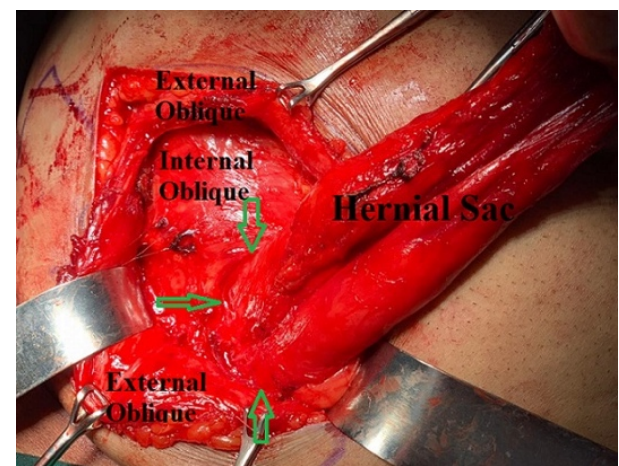

Fig. 4. Hernia sac dissected up to the neck marked by green arrows.
[12] Jamshidian M, Stanek S, Sferra J, Jamil T. Robotic repair of symptomatic Spigelian hernias: a series of three cases and surgical technique review. J Robot Surg. 2018 Sep; 12(3):557-560.

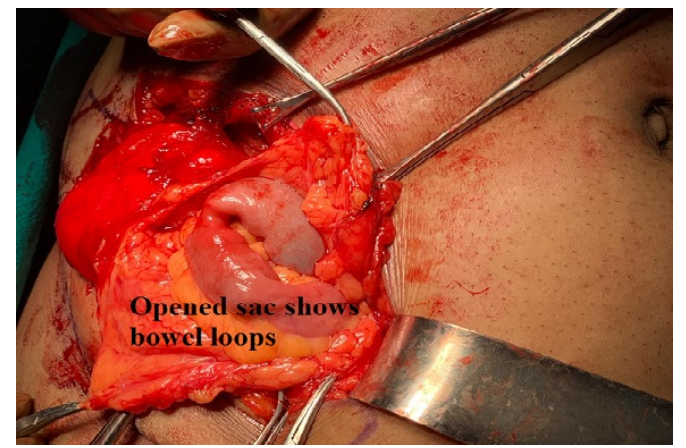

Fig. 5. Small bowel loop and omentum seen after opening the sac.

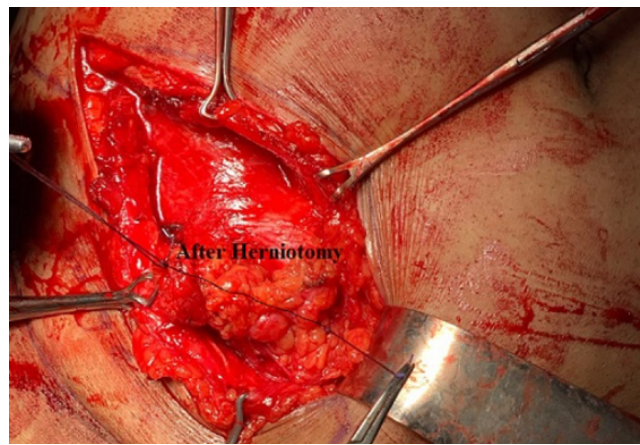

Fig. 6. Herniotomy completed

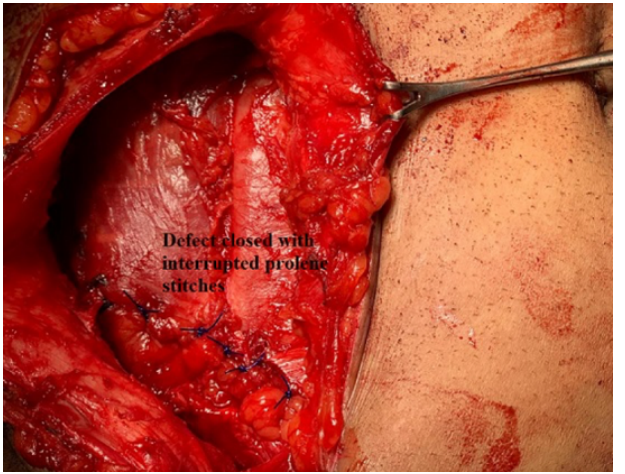

Fig. 7. Defect closed with interrupted polypropylene sutures.

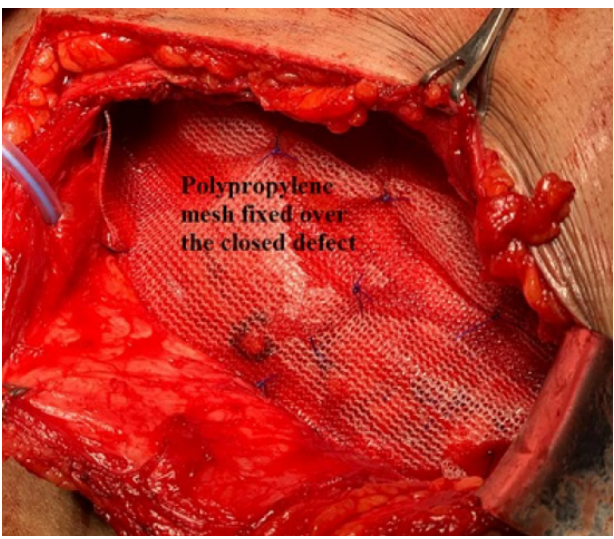

Fig. 7. Polypropylene mesh fixed over the closed defect. 